\section{(10)riginal Artirlwa.}

\section{THE RESPONSIBILITY OF THE MEDICAL PRO- FESSION FOR THE EARLY DIAGNOSIS AND PROMPT TREATMENT OF PULMONARY TUBERCULOSIS.*}

$$
\text { BY JOHN B. HAWES, 2D, M.D., }
$$

Assistant Out-Patient Physician, Director Tuberculin Department, Massachusetts General Hospital; Secretary Board of Trustees, Massachusetts Hospitals for Consumptives.

No one who has been intimately connected with tuberculosis work in Massachusetts the past five or six years can help but be impressed with the rapid advances made in seeking out, isolating and caring for that most dangerous and unfortunate of individuals, the advanced consumptive. It is also true, however, that one must be impressed with equal force with the fact that we are not getting at the incipient consumptive. For fourteen years the Rutland State Sanatorium has been widely known as an institution set aside for incipient cases of pulmonary tuberculosis; during the first twelve years, when patients were selected by special examinations, the number of really incipient cases out of the total capacity of 350 averaged $34 \%$; during the past two years, when any physician in the state could make application for admission of his incipient cases to Rutland, the percentage of those has fallen to $18 \%$ of the total number, although the incipient cases now in the other three state sanatoria would probably bring the number to approximately the same as were formerly cared for at Rutland alone. In addition to this, it is also probably true that the classification, according to which the patients at the sanatoria are classified as incipient, moderately advanced or advanced, is somewhat stricter than the more or less indefinite classification in use a few years ago.

It is important to have a clear idea of exactly what constitutes an incipient case of consumption. This, according to the classification of the National Tuberculosis Association, which is printed on the back of every application blank for admission to our state sanatoria, is as follows:

"Incipient. - Slight or no constitutional symptoms (including particularly gastric or intestinal disturbance or rapid loss of weight). Slight or no elevation of temperature or acceleration of pulse at any time during the twenty-four hours.

" Expectoration usually small in amount or absent.

"Tubercle bacilli may be present or absent.

" Slight infiltration limited to the apex of one or both lungs or a small part of one lobe.

"No tuberculous complications."

This description is clear enough to guide any one in classifying his cases. It is interesting to compare this with the following abstract of applications for admission of patients to Rutland handed in by Massachusetts physicians as of the incipient class:

* Read before the Boston Medical Library and Suffolk District Medical Society, Dec. 6, 1911.
A. Temperature 100.2, pulse 96 ; has lost $20 \mathrm{lb}$. in weight.

B. Temperature 100 , pulse 82 , sick four months, hoarse, weak, pale, easily out of breath, lost $30 \mathrm{lb}$.

C. Temperature 101, pulse 100, weak, pale, has tuberculosis of genito-urinary tract and has lost $75 \mathrm{lb}$. in five years.

D. Temperature 100.5, hoarse, weak, pale, has night sweats and has lost $27 \mathrm{lb}$.

E. Application No. 1, July 28 , handed in as "Incipient" by Dr. X. Sick two years, weak, pale, lost $17 \mathrm{lb}$. Application No. 2, handed in two days later by Dr. Y, for the same patient, as "advanced." Temperature 100 , pulse 96 , weak, pale and hoarse.

No more evidence than this is needed to show that, as far as the Rutland State Sanatorium is concerned, incipient cases are not generally discovered. Does the fault lie with the profession or with the public? Is it that the doctors do not, will not or cannot diagnose incipient tuberculosis, or is it because patients do not come to them until too late? Ten years ago or even less we should all have agreed that to a very large extent it was the fault of the public. But ten years of constant hammering at the public has made a vast difference. Tuberculosis exhibits, lectures and leaflets have accomplished wonders; the study of the disease has been introduced into schools down to the primary grades; churches have taken it up; it has been a favorite topic for discussion at meetings of labor unions, lodges and women's clubs, while on billboards, in newspapers and in pay-envelopes of working men, advice and information on the subject is ever present. The veriest school child knows that "consumption can be cured in its early stages," and every workman is fully aware that a "hemorrhage" is a sure sign of lung trouble. I fear we must shoulder most of the blame ourselves and acknowledge that we are at fault.

In a recent article, and one of the most valuable ones I have ever read, entitled "The Relation of the Physician to the Public Campaign against Tuberculosis," Dr. Hoyt E. Dearholt, executive secretary of the Wisconsin Anti-Tuberculosis Association, makes a striking indictment against the medical profession of his state as regards its ability to diagnose and to treat consumption. This investigation was carried on under the auspices of the Wisconsin Anti-Tuberculosis Association and involved a study of nine cities of varying size, and one county, and personal interviews with over 1,400 patients. A welltrained sociological student and experienced field worker with fourteen assistants was in charge of the work. Dr. Dearholt's figures do not reflect credit on the average Wisconsin physician as far as diagnosing and treating tuberculosis is concerned. For instance, out of 195 cases, each one registered by the physician as tuberculous, 60 , or nearly one third, were not told the nature of their disease, or else were deliberately lied to by the first physician consulted, while of 159 patients not registered as tuberculous by their physicians, 91 , considerably 
over one half, were either lied to or left in ignorance. I fear that my own figures will show that the state of affairs in Massachusetts is little if any better than that in Wisconsin.

At the last meeting of the British Association for the Prevention of Consumption, Sir William Osler said that the public were now alive to the necessity of dealing with tuberculosis in its early stages, but that doctors also needed education. If this is true in England, it is also certainly true in Massachusetts.

In studying this subject I first looked up outpatient records at two of our large hospitals in this city, the Massachusetts General and the Boston Consumptives' Hospital, with a view to finding out what was being accomplished, first, in the prompt diagnosis of tuberculosis, and second, its early diagnosis. The results as tabulated below are interesting. The first table is made up from 100 consecutive cases in which the diagnosis of "phthisis" or "pulmonary tuberculosis" was made at the Out-Patient Department of the Massachusetts General Hospital in the years 1903-1904.

TABLE NO. 1.

Odt-Patient Department, Massachusetts General Hospital.

One Hundred Cases of Pulmonary Tuberculosis, AvgUst, 1903,- Febrdary, 1904.

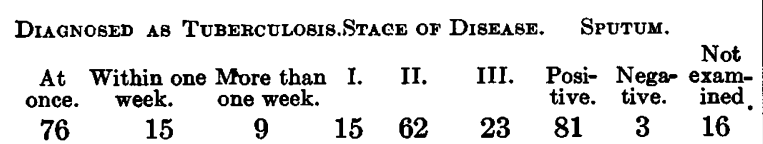

These figures are a striking tribute to the value of a routine physical examination including that of the sputum. Out of these 100 patients, 76 were diagnosed at once and 91 within a week, usually one to two days, or as soon as they could bring in their sputum. This was positive in 81 out of the 100 cases. As far as "prompt" diagnosis is concerned, this is an excellent showing. When we come to the results in early diagnosis it is very different; out of these 100/patients, only 15 were called incipient, and out of these 15 the sputum was positive in 12, leaving a grand total of 3 in which a diagnosis of incipient pulmonary tuberculosis was made without sputum containing tubercle bacilli.

The next table shows a similar series of cases from the same hospital only five years later.

\section{TABLE NO. 2.}

Out-Patient Department, Massachusetts General Hospital.

One Hundred Cases of Pulmonary Tuberculosis, November, 1911, - MAY, 1911.

Diagnosed as Tuberculosis. Stage of Digease. Sputum.

\begin{tabular}{|c|c|c|c|c|c|c|c|}
\hline $\begin{array}{c}\text { At } \\
\text { once. } \\
70\end{array}$ & $\begin{array}{l}\text { Within one } \\
\text { week. } \\
25\end{array}$ & $\begin{array}{c}\text { More than } \\
\text { one week. } \\
5\end{array}$ & 30 & $\begin{array}{l}\text { II. } \\
51\end{array}$ & $\begin{array}{r}\text { III. } \\
19\end{array}$ & $\begin{array}{c}\text { Posi- } \\
\text { tive. } \\
58\end{array}$ & $\begin{array}{c}-\begin{array}{c}\text { Nega- } \\
\text { tive. } \\
18\end{array} \\
18\end{array}$ \\
\hline
\end{tabular}

Here again the value of the routine examination is evident as shown by the 95 patients in whom a definite diagnosis was made either on the first visit or within a week, but here also there is nothing to indicate that much was accomplished in the early diagnosis. Out of this series of 100 cases, 30 were incipient, but of these only 14 were so classified without a positive sputum examination. These results show encouraging progress when compared to those of five years before, but the number of diagnoses of " Debility," "Anemia," "Neurasthenia," and " $\mathrm{Ph}$ ?" found in looking over these records would at least suggest that many really incipient cases are as yet undiscovered, for it is surely improbable that only 30 patients with incipient consumption came to such a large out-patient clinic as this during a period of six months.

Table 3 is a similar series of 100 cases from the Out-Patient Department of the Boston Consumptives' Hospital. I am indebted to Drs. E. A. Locke and S. F. Cox for permission to examine these records. The conditions here are quite different from those at the Massachusetts General Hospital, in that this clinic is known as one purely for consumptives and one in which, consciously or not, the physicians are keenly on the lookout for early signs of this disease.

TABLE NO. 3.

Odt-Patient Department, Boston Consumptives' Hospital.

One Hundred Cases of Pulmonary Tuberculosis, 1910.

Diagnosed as Tuberculosis. Stage of Disease. Sputum.

At Within one More than I. II. III. Posi- Nega- exam $\begin{array}{lll}\text { once. Week. one week. } & \text { tive. tive. ined. }\end{array}$ $\begin{array}{lcccccccc}91 & 2 & 7 & 27 & 47 & 26 & 44 & 31 & 25\end{array}$

It is evident that in the prompt diagnosis of the disease the figures of the Boston Consumptives' Hospital are about the same as those of the Massachusetts General Hospital for the same period. At the former, 93 out of the 100 patients were diagnosed within a week, compared to 95 at the latter. The proportion of incipient cases was also about the same -27 as compared with 30. While, however, out of the 30 incipient cases at the Massachusetts General Hospital only 14 were diagnosed as such without a positive sputum examination, at the Boston Consumptives' Hos nital, 20 out of 27 incipient cases were so classifie $a$ without bacilli in the sputum. The figures while small thus show differences in this regard, which in the long run will amount to a great deal. In my opinion it is very encouraging to see that a fairly large proportion of the incipient cases are diagnosed without the long and dangerous delay caused by waiting for positive sputum examinations.

So far this investigation would tend to show that, in our large out-patient departments in Boston at least, the diagnosis of pulmonary tuberculosis is very promptly made, but, on the other hand, very little evidence that many of the really incipient cases are being recognized. The number of cases in which the diagnosis was "deferred" or a provisional diagnosis made would suggest, as mentioned above, that this is so not because the patients do not come to the physicians but because the physicians were unwilling to make a definite diagnosis on the evidence as it presented itself to them. 
In the second part of this study I have endeavored to ascertain what the profession at large throughout the state is accomplishing, first, in the prompt diagnosis of consumption; second, in its early diagnosis; and, third, in the disposal of consumptive patients. There is obviously no way of getting at these facts from the physicians. Although I realize that statements from patients are often inadequate and misleading, by asking a fairly large number of patients in our state sanatoria a certain number of clearly worded questions I believe that I have obtained answers which fairly represent the truth. Through the kindness of the superintendents, printed cards like the one shown below were distributed to one hundred patients each in the North Reading, Lakeville and Westfield State Sanatoria, and to two hundred patients at the Rutland State Sanatorium. At the first three institutions the cards were given to the patients, who wrote out their own answers; at Rutland the physicians asked the patients the questions and wrote down the answers on the cards. The cards were signed with my name and returned to me by the superintendent after being filled out. The following are the questions which patients were asked to answer:

1. Name or Initials. ............ Date......... Date of Entrance. .............

2. Sanatorium ........................................

3. When did you first suspect you had any lung trouble?

5. For what special symptom or symptoms did you go to

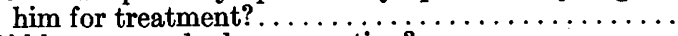

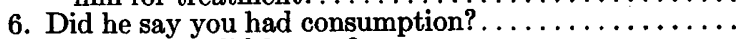

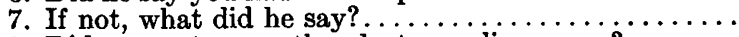

8. Did you go to any other doctor or dispensary?.......

9. How many doctors did you go to? . . . . . . . . . . .

10. When were you first told definitely that you had consumption? ...........................................

11. When did you apply for admission to the Sanatorium?

From the answers to these questions I hoped to find out, among other things, first, whether the patients went to a doctor as soon as they even suspected they might have lung trouble or whether they waited before so doing; second, whether the doctor told these patients, who later proved to have consumption, that they had tuberculosis, and if not, what explanation he gave to them regarding their illness; third, whether the doctor who said their patients did not have consumption did so because of inability to detect the disease, fear of making a mistake, unwillingness to tell the truth to the patient, or failure to use simple and plain enough language so that the patient clearly understood his position; fourth, I hoped to find out whether the physician, having made a definite diagnosis of consumption, advised immediate treatment at a sanatorium or allowed the patient to take home treatment more or less rigidly enforced. A summary and analysis of my replies follows:

TABLE NO. 4.

Table showing Number of Patients who Never Suspected that They had Lung Trouble until so Told by a Physictan.

$\begin{array}{ccccc}\text { N. R. } & \text { L. } & \text { W. } & \text { R. } & \text { Total. } \\ \mathbf{1 5} & \mathbf{7} & \mathbf{4} & \mathbf{5 1} & \mathbf{7 7}\end{array}$

This table shows that, out of the 500 patients questioned, 77 went to a doctor for treatment of a cough or for some other condition, but did not suspect any serious lung trouble to be present; the remaining 423 patients definitely stated when they first thought they had anything wrong with their lungs and when they first went to a physician. This is shown in the next table.

TABLE NO. 5.

Table showing Patients who Consulted a Physician at once, Those who Waited, and the Length of This InTerval.
N. R. L. W. R. Total.
$\begin{array}{rrrrr}28 & 11 & 11 & 54 & 104 \\ 61 & 78 & 73 & 119 & 331\end{array} \begin{gathered}\text { "Never suspected they had } \\ \text { any lung trouble"; or an- } \\ \text { swers not considered. } \\ \text { Went to a physician at once. }\end{gathered}$
$\begin{array}{rrrrrl}2 & 0 & 8 & 1 & 11 & \text { Waited one month or less. } \\ 9 & 11 & 8 & 26 & 54 & \text { Waited more than a month }\end{array}$

As given above, 331 out of the 500 patients said they consulted a physician as soon as they suspected any lung trouble; to this number might be added many of the 104 who " never suspected any lung trouble," but who nevertheless probably went to a physician for treatment fairly promptly. The striking fact about these figures is the comparatively small number, 54, who delayed more than one month before consulting a doctor. This gives fairly strong evidence that the lack of prompt and early diagnosis is not because the average patient does not go to the doctor or dispensary soon enough.

\section{TABLE NO. 6.}

Table showing Chief Symptoms for which Patients Consulted Their Physicians.

\begin{tabular}{rrrrrl} 
N. R. & L. & W. & R. & Total. & \multicolumn{1}{c}{ Symptoms. } \\
55 & 46 & 53 & 106 & 260 & Cough, Cold, Grippe. \\
24 & 23 & 20 & 58 & 125 & Weak, tired, run down. \\
15 & 13 & 12 & 8 & 48 & Pain in chest. \\
8 & 14 & 16 & 43 & 81 & Hemorrhage.
\end{tabular}

This table needs no comment. It shows in a striking way the four great groups of symptoms for the treatment of which patients with consumption go to their physicians. The last symptom, "hemorrhage," deserves further comment, as the following figures will show:

TABLE NO. 7.

Table showing Number of Cases in which Patients Consulted a Physician on Account of Hemorrhage, and the Physicians' Answers as to whether or not It Meant Tuberculosis.

N. R. L. W. R. Total.

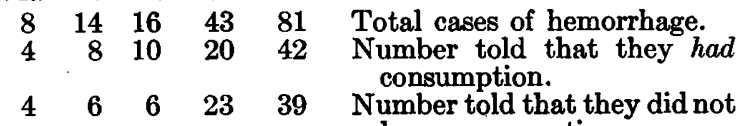

$\begin{array}{llllll}4 & 6 & 6 & 23 & 39 & \begin{array}{c}\text { Number told that they } \\ \text { have consumption. }\end{array}\end{array}$

As stated earlier in this paper, I believe that the general public knows that in $99 \%$ of cases a "hemorrhage" means consumption. It is a somewhat striking commentary on Massachusetts physicians, however, that out of 81 patients who had had hemorrhages, all of whom turned 
out later to have consumption, 39 were told by their physicians that the hemorrhage did not mean consumption. The following figures are of equal interest:

TABLE NO. 8.

Table showing Number of Patients said to have Consumption and those said not to have ConSUMPTION.

$\begin{array}{ccccc}\text { N. R. } & \text { L. } & \text { W. } & \text { R. } & \text { Total. } \\ 33 & 42 & 40 & 100 & 215 \\ 67 & 58 & 60 & 100 & 285\end{array}$

Patients who were told they did have consumption.

Patients who were told they did not have consumption.

These figures mean that out of 500 consumptives, many of whom, at least $75 \%$, were in the advanced or moderately advanced stages of the disease, 285 were told by the first physician whom they consulted that they did not have consumption, or, what is perhaps worse, were not told by their physician in such a way that they could grasp the fact that they did have consumption.

The answers given to patients by their doctors who told them they did not have consumption I have grouped as follows:

TABLE NO. 9.

Table showing Diagnosis given Patients by Their Physicians who said They did Not Have ConSUMPTION.

$\begin{array}{rrrrrl}\text { N. R. } & \text { L. } & \text { W. } & \text { R. } & \text { Total. } \\ 10 & 21 & 22 & 20 & 73 & \begin{array}{l}\text { Bronchial trouble, bronchitis, } \\ \text { cold, grip. }\end{array} \\ 18 & 7 & 11 & 22 & 58 & \begin{array}{l}\text { Run down, needed rest. } \\ 22\end{array} \\ 10 & 11 & 5 & 48 & \begin{array}{c}\text { Spot on lungs, weak lungs, } \\ \text { lung trouble, lungs affected. }\end{array}\end{array}$

There were many other answers of all kinds. Some doctors simply said there was nothing wrong with the lungs; one patient at a large Boston clinic was told that he had " a tubercular affection of his right apex," while another was content to have " rough breathing at his left base "; neither patient grasped the fact that he had consumption. The 48 patients in the last group, who were told that they had " a spot on their lung, weak lungs, lung trouble, or lungs affected," seem to me a particularly pathetic class, as here, in most cases, the doctors evidently knew the correct diagnosis, but did not impart this fact to the patient.

Comparatively few of these patients were content to visit only one doctor, and those who did were practically all among those told at once that they had consumption. Of the other class, many patients said they visited three, four or even ten or fifteen physicians before getting a satisfactory diagnosis. The figures are shown below:

TABLE NO. 10.

Table showing Total Number of Doctors Visited by Five Hundred Patients.

$\begin{array}{ccccc}\text { N. R. } & \text { L. } & \text { W. } & \text { R. } & \text { Total. } \\ 202 & 224 & 234 & 468 & 1,128\end{array}$

I was interested in finding out how soon it was after the patient first visited his physician that he clearly and definitely understood that he had consumption. This is shown in the following table:

\section{TABLE NO. 11.}

Table showing Time after First Visit to Physician that Patients were Definitely Told that They had Consumption.

\begin{tabular}{|c|c|c|c|c|c|}
\hline $\begin{array}{l}\text { N. R. } \\
29\end{array}$ & $\begin{array}{l}\text { L. } \\
4\end{array}$ & $\begin{array}{l}\text { w. } \\
3\end{array}$ & $\begin{array}{l}R . \\
4\end{array}$ & $\begin{array}{l}\text { Total. } \\
40\end{array}$ & $\begin{array}{l}\text { Never told they had consump- } \\
\text { tion. }\end{array}$ \\
\hline 37 & 34 & 43 & 93 & 207 & at once. \\
\hline & 12 & 15 & 40 & 76 & $\begin{array}{l}\text { old in one month or less } \\
\text { after first visit. }\end{array}$ \\
\hline & 31 & 39 & 59 & 148 & Told after one month or more. \\
\hline
\end{tabular}

Out of the 500 patients as shown in the above table, 40 said that they were never told that they had consumption and 148 had to wait at least one month, which in many instances amounted to six months or one or two years. Even the 207 patients who were told at once is not a very creditable showing out of 500 patients who already had tuberculosis at that time.

\section{TABLE NO. 12.}

Table showing Interval between First Visit to Doctor and Time of Applying for Admission to a SANATORIUM.

N. R. L. W. R. Total.

$\begin{array}{llllll}19 & 25 & 21 & 52 & 117 & \text { Made application at once. }\end{array}$

$\begin{array}{lllllll}13 & 18 & 14 & 43 & 88 & \text { Made application in one }\end{array}$ month or less.

$\begin{array}{llllll}22 & 15 & 24 & 60 & 121 & \text { Made application after one }\end{array}$ $\begin{array}{llllll}37 & 28 & 41 & 39 & 145 & \begin{array}{c}\text { month, less than six months. } \\ \text { Waited over six months be- }\end{array}\end{array}$ $\begin{array}{lllll}37 & 41 & 39 & 145 & \text { fore applying. }\end{array}$

From these figures I have tried to find out how soon it was after the patient first visited a physician that any steps were taken to get him into a sanatorium for treatment. Out of the $500 \mathrm{pa}$ tients, 117 applied for admission at once and 205 applied within one month. These figures are encouraging, and it is to be hoped that as the value of sanatorium treatment and the knowledge of Massachusetts facilities in this line become more widely known, that the proportion will increase. Out of the 145 who waited over six months before trying to get into a state sanatorium, there were undoubtedly a few who received adequate treatment elsewhere. Most of them, I fear, continued at their work or else carried out an only too inefficient home treatment.

One very natural criticism of the figures above given will be that I am basing my conclusions upon patients' statements and not upon scientifically proven statistics. When, for instance, I state that 331 patients out of 500 went to a physician " at once" or soon after they suspected any lung trouble, I fully realize that how soon any patient will be led to believe that a cough, loss of weight, weakness, etc., means "lung trouble," and will go to a doctor to see about it, is a very variable quantity. I also realize that in many instances it was due to the patient's stupidity, ignorance or stubbornness, and not to any fault on the part of the doctor that the patient did not realize the gravity of the situation and 
need of prompt and energetic treatment. In spite of all this, however, and making all due allowance for the inaccuracy and misstatements in the replies given me by these 500 patients, the results show that the average physician either fails to make a diagnosis of pulmonary tuberculosis in its early stages, or at least fails to inform the patient, and, what is more reprehensible, fails to institute a course of treatment which shall give him the best chance of recovery and shall properly protect the community from further spread of the disease.

Among the numerous causes for this state of affairs, I would place first the lack of a routine thorough physical examination. The figures given in the first part of this paper show the great value of this. Out of 300 patients at the Massachusetts General Hospital and the Boston Consumptives' Hospital, 279 were given a definite diagnosis at the first visit, or within one week. Next, I believe that undue haste will account for many errors. The busy practitioner with an office full of patients must find it very difficult to go over the details of every suspicious case. It is certainly his duty to do so, however, or else to send the patient to some one with more time and knowledge. Third, I do not think that the average physician is sufficiently open and frank with the patient whom he finds to have, or suspects to have, consumption. This is due, in my opinion, first to fear of frightening the patient, and, second, to an unwillingness to risk making a definite diagnosis on what he considers insufficient evidence. Finally, I do not. believe that the average busy practitioner is able to judge and sum up the many minute bits of evidence on which the real early diagnosis of tuberculosis is based.

I would make the following suggestions which may be of value in bringing about a better condition of affairs as regards the prompt and early diagnosis of consumption:

(1) Every patient, or at least every patient in whom there is the slightest suspicion of lung trouble, should receive a routine physical examination with the patient stripped to the waist. Examination of the sputum should be a part of this routine.

(2) A " hemorrhage" should be considered as definitely indicating consumption unless there is clear evidence to the contrary, which there practically never is. Furthermore, the patient should be told so.

(3) Do not put off making a definite diagnosis until you find bacilli in the sputum. The real " early" diagnosis should be made long before bacilli appear in the sputum, and, indeed, it may be said that after bacilli appear there can no longer be an early diagnosis.

(4) Look more at the patient himself and his history and less at his lungs.

(5) In every doubtful case make the patient keep a record of his temperature and pulse, taken at the hours of $8,12,4$ and 8 , and report in a week.

(6) Talk plainly, openly and frankly with the patient, and if he has consumption see that he knows it. Err on the side of aggressive, early and efficient treatment.

(7) If the patient has consumption, try to get him in a sanatorium or hospital at once. Even if he will stay but a month or six weeks, he will there learn more than in a much longer time at home.

\section{SUMMARY AND CONCLUSION.}

(1) At the Massachusetts General Hospital and at the Boston Consumptives' Hospital, where there is a thorough routine physical examination of every patient and the sputum, consumption is diagnosed promptly, as shown by the fact that 279 out of 300 , or $90 \%$ of patients, were diagnosed at once, or within one week.

(2) At the same institutions, though less so at the latter, there is little evidence of much in the way of "early" diagnosis. Out of 200 patients diagnosed as pulmonary tuberculosis, 57 were found to be incipient, but of those only 34 were so called without a positive sputum examination, while during the same period at the Massachusetts General Hospital, at least, the number of cases of "debility," " anemia," "Ph?" and other somewhat vague diagnoses was very large.

(3) Out of 500 patients now at the various sanatoria in this state, over $75 \%$ of whom are in the advanced or moderately advanced stages of the disease, 285 were told by the first physician whom they consulted that they did not have consumption.

(4) Of these 500 patients, 331 stated that they went to a physician as soon as they suspected that they had any lung trouble. This might have been late or early in the disease, according to the intelligence of the patient. Only 54 waited over a month before consulting a doctor.

(5) Out of 81 patients who consulted a doctor because of a hemorrhage, 39 were told that it was not due to consumption.

(6) Of the 285 patients told that they did not have consumption, 73 were told by their doctors that they had bronchial trouble, bronchitis, cold or grippe; 58, that they were run down and needed a rest; and 48, that they had a " spot on the lungs," weak lungs, lung trouble, or that their "lungs were affected."

(7) These 500 patients visited 1,128 doctors in order to get a diagnosis.

(8) Of these 500 patients, 207 were told at once that they had consumption, 76 within a month, 148 waited over a month, and 40 were never told.

(9) One hundred and seventeen patients applied for admission to a sanatorium at once, 88 in one month or less, while 145 patients waited six months or more before applying.

DISCUSSION.

Dr. J. F. A. Adams: Dr. Hawes' investigation is of great practical importance, and his conclusions are somewhat startling. The subject interests me profoundly for several reasons. I was for six and a half 
years one of the examiners for Rutland, and for one year was a member of the Rutland Board of Trustees. I am president of a local anti-tuberculosis association which now maintains a small sanatorium or camp.

The case against the physicians is very strongly supported by Dr. Hawes' investigation, but there are two pretty strong arguments for the defense.

First. The interval of four to six weeks between the application for a sanatorium and the vacancy often allows time for an incipient case to become advanced.

Second. The testimony of patients should be taken with great allowance, for we all know that patients have a very poor memory for the details of their cases, and what has been said to them by physicians; and are very ready to lay blame for their condition upon anybody but themselves.

Nevertheless, it seems impossible to wholly reject Dr. Hawes' conclusions that "the average physician either fails to make a diagnosis of pulmonary tuberculosis in its early siages, or at least fails to inform the patient, and, what is more reprehensible, fails to institute a course of treatment which shall give him the best chance of recovery and shall protect the community from further spread of the disease." This is a rather strong indictment of the physicians of Massachusetts, whom we are accustomed to consider as particularly well educated and conscientious. If, therefore, these conclusions are correct, there must be some reasons for the failures they indicate which need investigation. Let us consider in order the three points of alleged failure.

First. Why does the average physician fail so often to make a diagnosis of pulmonary tuberculosis in its early stages?

It may be said in reply that this is a difficult thing to do and is a task better suited to the specialist than to the average practitioner. The definition of incipient tuberculosis has been changed within a few years, and I think there are many physicians who are not aware how restricted it is, even though it is printed on the back of the application blanks. In an incipient case, all general symptoms are practically excluded, cough and bacilli may be absent, and the only essential for a diagnosis is a small localized lesion, of which the physical signs may be very obscure. These signs may escape detection by a physician whose hearing is not acute, or who is not much in the habit of examining the lungs, or who is in a hurry, or who does not remove the patient's clothing and go over the whole chest with the stethoscope. There is no excuse for neglecting the examination of sputum, since this is done without charge by the State Board of Health, and yet I occasionally meet with physicians who did not know this until I told them. When the culture is negative, I think physicians are prone to attach too much importance to this fact.

It is not surprising that in some cases, the physician fails to discover the lesion, and still less so that the cases are many in which he finds himself in a state of doubt. The trouble here is that doubt is dangerous; and this brings us to the second point.

Second. Why do physicians fail to inform the patients?

With a negative culture, an absence of general symptoms and vague physical signs, it is not to be wondered at that physicians hesitate, and I believe there are many excellent practitioners who honestly believe that, under such circumstances, they are not justified in taking so momentous a step as to tell the patient that he has consumption. This is due to the belief that the mental shock will do the patient harm, and that this shock should be avoided unless he is pretty sure of his diagnosis. We are still more or less under the in- fluence of the old belief that consumption is incurable, and that it is a kindness to the patient to keep him in ignorance of his condition. But it is high time that physicians should base their actions upon the knowledge that consumption is curable, if taken in its earliest stage, and with the patient's knowledge and cooperation, but that postponement and concealment inevitably lead to disaster. Consequently, in cases of doubt, since risks must be taken, it is better to make an erroneous positive diagnosis than a negative one, for the same reason that the fire department turns out, even for a false alarm.

The wise course, therefore, is for the physician who is in doubt to frankly tell the patient of his suspicions and use every possible means of settling the question, including consultation with another physician-a specialist if possible.

Third. Why do physicians so often fail or delay to send their incipient cases to a sanatorium?

For this several reasons are assignable:

(1) Uncertainty of diagnosis, causing one to fear making a mortifying mistake.

(2) The patient's positive refusal to go.

(3) The patient's unwillingness to go, and lack of sufficient time or interest, on the physician's part, to go into long explanations, and urge and insist upon this procedure

(4) The patient's inability to pay the price of board at Rutland. This difficulty is now removed, but until recently it has been a definite obstacle.

(5) The belief entertained by some physicians that home treatment is just as good or almost as good as a sanatorium. The many published articles on home treatment tend to promote this belief, both with physicians and patients. It should be taught that home treatment is most valuable after the method has been learned at a sanatorium.

(6) The natural preference of physicians to retain control of their own patients, and of patients to remain under the care of their family physician.

(7) The belief which has obtained some currency that Rutland has lost its character as a sanatorium for early favorable cases and is filling up with advanced cases, making it a less cheerful place than formerly.

While we cannot shut our eyes to the stubborn facts which Dr. Hawes has so forcibly presented to us, it is evident that there are reasons for the present unsatisfactory conditions, all of which cannot be included under the term "reprehensible." The practical question is, "What can be done to remedy the existing evils?"

It seems to me that some change might advantageously be made in the method of admitting patients to the state sanatoria, and that this might be by the adoption of one of the two following plans:

(1) Return to the former plan of examinations for Rutland, by the appointment of examining physicians. I would modify this, however, by increasing the number of examiners, so that applicants need not go far from home to be examined.

(2) If the present plan is retained of allowing any registered physician to make the examination, an effort should be made to stimulate them to do more painstaking work. The present application blank only asks the physician to state whether the case is "Incipient," "Moderately Advanced," or "Advanced"; and it is not definitely stated that this diagnosis is to be based upon a careful physical examination. It would be a great improvement, in my opinion, if it were printed on the blank that a physical examination is required, a space provided for the details of the examination, and a diagram of the chest for indicating the site of the lesion, with a code 
of symbols, on the reverse side, to represent the usual physical signs. With this blank before him, I believe the average physician would take more pains, and that the office through whose hands the applications pass would be able to form a better idea of the actual stage of the disease. The educational value to the physician, also, is not to be overlooked.

There is another aspect of the subject upon which Dr. Hawes has not laid much stress, but which appears to me to be one of the causes for the concealment of incipient cases. So much pains is being taken in factories and shops to prevent infection by weeding out tuberculous employees that operatives or clerks who think they may have trouble with the lungs will avoid physicians and keep out of sight of the welfare nurse for fear of losing their employment or being turned out of their boarding-house or being shunned by their comrades. This is an indirect result of the beneficent anti-tuberculosis movement, which time may be relied upon to remedy.

I had hoped Dr. Hawes would report that the apparent scarcity of incipient cases is due to diminished infection resulting from the wide application of preventive measures. This is what we are all looking for, and I trust the time is not far distant when we shall find it to be an accomplished fact.

Dr. A. T. CABOT: I would first like to say a few words about the question asked by Dr. Adams, or suggested by his remarks, that there is a general feeling that Rutland is no longer reserved for incipient cases. There was never any change in the intention of so reserving it; but with the change in the method of admission, that is, allowing any physician in the state to make out an application for Rutland, we at once found that we were getting, as Dr. Bartlett has said, advanced cases which were marked on the blanks as incipient. We tried to correct that in a variety of ways. By considering the temperature and pulse records and the loss of weight, etc., we were able to eliminate a good many, but still these advanced cases continued to come in.

About three months ago we adopted the plan of sending a letter to the doctor making the application to ascertain whether the patient had improved or whether he had run down while waiting for admission, and to learn in other ways whether it was a favorable case. Since that method has been adopted there has been a very great improvement in the condition of the patients admitted, and in the past two months the class of cases has been as good as under the old system of selected examiners.

We are now putting into form a fuller blank, giving a chart for the chest examination.

I think a very great advantage of the present system is that it will have a distinctly educating effect upon all the physicians sending patients to us, for where a patient has been in the sanatorium a few days, long enough to make a careful examination, a card is sent to the doctor who recommended that patient, giving exactly the diagnosis made in that case at the sanatorium. The physician in question is thus able to compare his own estimate of the stage of the disease with ours. That, I think, has had a good effect and will continue to have a good effect.

The responsibility for the discovery of consumptives in the state of Massachusetts rests with the medical profession, and it ought to be left on their shoulders. If you have a few examiners about the state the rest of the physicians will say, "It is up to them to hunt out the tuberculosis cases and send them to the sanatoria." The present system of admission to the state sanatoria puts an end to such a shifting of responsibility.

It is, then, particularly important that these observations of Dr. Hawes should be brought to the attention of the medical profession and widely discussed by us.

Much is being done by laymen and legislators to supply the means and the machinery for this campaign against tuberculosis, and to better the condition of the community by education, by improving the conditions under which people live and work and by enforcing the health laws. This work of prevention is of the greatest importance, is a vital part of the world's endeavor in this cause and must have our support and assistance in every possible way. In this work we share the responsibility with the rest of the community.

But preventive measures will not alone suffice; the great mass of tuberculosis already existing in the world must be attacked and the responsibility for the intelligent and thorough management of this part of the campaign rests on the shoulders of the medical profession. They must find the cases and wisely advise them, not only with regard to the best treatment in their particular circumstances, but in regard to the precautions necessary to prevent their infecting their family and friends. These duties to the patient and to the community require in almost every case that the patient should clearly understand the nature of the trouble.

It is inconceivable that a patient with pulmonary tuberculosis can be induced to undergo the rigid course of treatment necessary for his cure, involving as it does an entire change in his habits of life, without telling him the reason of it all. This does not need to be told to him brutally; he may, when it seems wise, be told that he is threatened with tuberculosis or that he has a condition that will lead to consumption if he does not at once take the needed precautions. Such a tentative opinion may be sufficient in a case where the diagnosis is made at a time when there is no expectoration, and, therefore, little or no danger of infection of other people. When there is, however, an expectoration that is endangering others, the full truth should be told him, for only in that way can he be led to see the importance of the precautions which are essential to the safety of others.

The fact that tuberculosis, when taken in time, can be so frequently cured, is becoming known throughout the community and makes the knowledge of the nature of his malady less shocking to the patient.

Such considerations seem to point out the duty of the physician who makes a correct diagnosis.

What can be said for the man who prescribes for a consumptive patient without making an examination?

There may occasionally be a case of incipient disease in which symptoms pointing to the lungs are wholly wanting.

Such cases are, however, rare and few if any of the cases investigated for the study that Dr. Hawes has made were of this variety.

I fear we must acknowledge that there is a widespread habit among doctors to prescribe for a cough without trying to learn the condition of the lungs.

Such neglect is indefensible. It should be condemned in the most unqualified manner by all conscientious practitioners.

The profession should make it clear that it does not condone such slipshod practice, for the laity are beginning to take notice and we must expect criticism from outside which will, perhaps unreasonably but not unnaturally, diminish the high esteem for medical art.

Dr. P. Challis Bartlett: Dr. Hawes's paper makes a strong plea for finding the cases of pulmonary tuberculosis early. I see the patients after the physicians in private practice have sent them to us; I see the other side of the proposition, and for that reason take a little different view of the case from Dr. Adams. Dr. Cabot 
will undoubtedly answer some of the statements Dr. Adams has made in regard to increasing the efficiency of the application blanks for admission to our sanatoria.

The amount of work that has been done in the effort to find a cure for pulmonary tuberculosis is enormous. Every few months some new specific is discovered and rejected, but the fact remains that when a case of this disease is discovered early and the present methods of treatmen' are carried out intelligently, from 60 to $80 \%$ of the patients recover. It doesn't need any new specific; it doesn't need anything but the early discovery of the cases to get an arrest of the disease. When a specific is found, we will gladly use it, but no specific is going to replace with normal lung tissue an area that is well infiltrated with tuberculosis. The early diagnosis is, therefore, of the utmost importance; we should make, therefore, every effort to detect our cases early before the lung has broken down and bacilli appear in the sputum.

Dr. Hawes spoke of making the diagnosis and telling the patients that they have tuberculosis before we find bacilli in the sputum. When we find bacilli in the sputum it means that the lung has broken down, and in many cases that the patient is no longer in the incipient stage. But to obtain the most favorable results in this disease it is necessary to get the case very early. Then and only then can we be reasonably sure that the patient after treatment will get along comfortably and resume his place in the world.

Some of the very best of our incipient cases at the Rutland State Sanatorium are sent to us for examination by patients or ex-patients. Some patients with this disease become very acute in noticing symptoms of the disease in others, even before the bad cough or spitting appear. It is just as Dr. Hawes says, - it does not need a physical examination of the chest necessarily to make a diagnosis; these patients and one to the other and are obliged to wait until they finally realize it themselves, and when they do realize it know that it is too late. We have many such cases and their attitude naturally is not a pleasant one.

I have taken the patients admitted to the Rutland Sanatorium during the last six months and compared their classification as given on their application blanks as made out by their physicians with the classification as made out by our physicians on admission. It is true that a very few of these patients were not admitted for eleven weeks after their applications had been made out, but the greater number were admitted within four weeks; in the table that I will show, all the female patients had been admitted within four weeks of their application and some of them had been admitted within one week.

On the applications there were given 195 incipient cases, 72 moderately advanced, 6 far advanced; on admission our physicians graded them as 73 incipient, 144 moderately advanced and 59 far advanced.

In these far-advanced cases we followed as closely as possible the classification of the National Association. As I said, in some of these cases, to be sure, eleven weeks had elapsed from the time their own physicians had examined them to the time of admission. That unquestionably places a good many of the moderately advanced into this class of far advanced, but it cannot place many of these incipients from that class to the far advanced. Patients do not, as a general rule, unless it is the very rapid tubercular case, go from incipient to advanced in a few weeks. We had one case whose application showed a moderately advanced process who was admitted within four weeks and died four hours after admission. We have had many others that died within a few weeks after admission whose applications showed that they were incipient on examination. Surely there is some mistake either in the reading or understanding of the classification because the average

Rutland State Sanatoridm.

Variation of Classification of Patients on Application and at Admission. Six Months, - May 1 to Oct. 31, 1911.

On Application.

Incipient,

Moderately advanced,

Far advanced,

Not classified,

Total,

$$
\begin{array}{r}
\text { Male } \\
85 \\
35 \\
3 \\
1 \\
\hline 124
\end{array}
$$

ale. Female. Tot

\begin{tabular}{rr}
110 & 195 \\
37 & 72 \\
3 & 6 \\
3 & 4 \\
\hline 153 & 277
\end{tabular}

On Admisaron.

Male. Female. Total.

22

$\begin{array}{llr}22 & 51 & 73 \\ 70 & 74 & 144\end{array}$

32

$\overline{124}$
27

1

153

\begin{tabular}{cc}
\multicolumn{3}{c}{ Total. } \\
On application. & On admission. \\
195 & 73 \\
72 & 144 \\
6 & 59 \\
4 & 1 \\
$\frac{1}{277}$ & $\overline{277}$
\end{tabular}

ex-patients become so keen in observing the early / case of tuberculosis does not progress from incipient to symptoms that they detect them in their immediate advanced in a few weeks.

family and friends and send them to some one for a diagnosis. These cases are among the earliest that we have. It is unfortunate that more early cases do not realize these early signs and symptoms because as it is many patients never seek medical advice until the disease has become well marked.

There are, however, still a large number that seek medical advice early añd are, for one reason or another, not diagnosed as tuberculous until it is too late. $\mathrm{Pa}$ tients who go for advice and are put off for one reason or another until they become moderately advanced or worse, want to know the reason for this. They find that their disease could possibly have been arrested if they had been diagnosed earlier. They realize that they are hopeless invalids, that though they may live for years they are shut out from their, work and will have
to take sanatorium or home treatment for the rest of their lives; they want to know why it is that when they have been to physician after physician they are not told that they have tuberculosis, but simply go from

Tuberculosis can be diagnosed in its incipiency. The responsibility rests upon us to make this diagnosis before the patient becomes a hopeless invalid.

Dr. F. C. ShatTuck: I do not pretend to be an expert in tuberculosis, although I have had a long and large experience with it. For many years I had a six months' service, with daily visit, at the House of the Good Samaritan, where about $50 \%$ of the cases were of consumption. In 1885, I read a paper before the Climatological Society on "The Home Treatment of Consumption," and until within a few years I had my fair share of experience with it in private practice. Dr. Hawes' paper is highly statistical. The only way to combat statistics is with statistics. I have no desire to combat the paper, and I have no statistics to combat it with if $I$ had the desire.

Dr. Hawes seems to show pretty clearly that we are sinners. Whether we are such miserable sinners as the primary depressant influence of his paper might lead us to deem ourselves, I am not quite sure. There are 
many factors which come into this question, prominent among which is one that he mentions, namely, the unreliability of the statements of patients. There isn't one of us who has not had reason, over and over again, to have driven home to him how unreliable are such statements, whether with regard to themselves or to their physicians. They, like the rest of us, are prone to put blame upon others rather than upon themselves. Still, with due discount for this fact, I have no question that Dr. Hawes has justification for his indictment.

Looking back on my own experience, I confess that I have sinned, in spite of having tried to be pretty careful, from failure to detect early tuberculosis. I have sinned also perhaps in minimizing the state of the case to patients, but that was in the days when there were no sanatoria, and before we knew the danger of the spread of the disease through sputum. In many cases it seemed wiser not to use the word "consumption" at the risk of alarming and taking away hope from the patient when the best thing possible for that particular patient could be done without using a word of fatal import in the popular ear.

It seems to me that the practical lesson which we should take to heart from what Dr. Hawes has told us to-night, and what we have heard from other speakers, can be briefly stated:

First: We must be very careful and thorough in our examination, taking nothing for granted.

Secondly: We must not wait until every kind of evidence is in before making a diagnosis. We must not wait until the rational signs, the physical signs and the sputum examination all concur, but must be ready to make at least a provisional diagnosis on any one of them. From a therapeutic point of view it is safer to call that tuberculosis which is not so than to make a mistake in the opposite direction.

Thirdly: We must be frank with our patients, stating our opinion and advice in unmistakable terms.

DR. Alfred Worcester: This severe indictment of the family physician may be deserved. As one of the condemned class, perhaps I ought to thank the reader for his moderation. I certainly am under obligation to him for his courtesy in giving me an advance reading of his most interesting paper and also this opportunity to say a few words in our behalf. The general practitioner who must help families in all their troubles and who, because thus forced to know something about the whole body and every disease, cannot know everything about any particular disease, may from the standpoint of the specialists seem either dishonest, or ignorant, or both. Such, I take it, is the real conclusion that Dr. Hawes expects will be drawn, but out of kindness restrains himself from drawing, from his tables as regards the majority of the physicians of this commonwealth who have succeeded in sending their tubercular patients to the state hospitals. At any rate, we are getting used to this sort of rating. And we are learning not very slowly that our highest function is in referring patients to the ever-increasing variety of specialists.

I will not take your time in describing how the specialists appear from the standpoint of the family physician. But I want to point out that one large cause of the misunderstanding between us is to be found in the fact that the family physician has to take account of many factors in the case which the specialist perhaps cannot, and however that may be, often does not even consider. Thus, besides the disease itself, there are sometimes other diseases from which the patient suffers, and various interests, that the family physician cannot overlook. For instance, in this special matter of incipient tuberculosis, it would be interesting to know in how many of these cases tabulated by Dr. Hawes, the hus- band or wife or parents, after having been promptly and truthfully told the facts, had besought the physicians not to tell the patients themselves, at least until proper provision could be made for their hospital treatment.

Another mitigation for the condemned might be found in the fact that, while formerly only such cases as the young house officers would accept as incipient were admitted to the Rutland Sanatorium, in the last two years, which the paper considers, the impression has become current that advanced cases would be as readily accepted there.

Again, what if it is true that many general practitioners have failed to accept the classification recommended by the National Tuberculosis Association, how does that prove that tuberculosis in its incipient stages is not generally discovered? Is it not just as likely that these physicians who are accustomed to seeing many of their patients recover from tuberculosis, even without sanatorium treatment, misuse the term "incipient" in describing patients whom they consider still curable, or whose disease at least may be arrested. It may not be amiss to state here the fact that some patients who were refused at the Rutland Sanatorium as incurable have since recovered at home.

I protest against the necessity of telling every tuberculous patient he is a consumptive. In the case of tuberculous glands or joints, tubes or testicles, peritoneum or pleura, it would be admitted perhaps even by Dr. Hawes that it would be a mistake to label the patient as a consumptive. So also it often is in cases of localized tuberculosis of the lungs. For is it not shown by the cicatrices found at autopsy how very commonly such lesions are recovered from? Why not reserve the unscientific term "consumption" for the septic infection which may supervene?

I fail to understand the reader's objection where the patient was told the apex of his lung was affected with tuberculosis. That is what I should have told him, if I had found such to be the fact. And as regards the early diagnosis of bronchitis, grippe, and even " rundown," in patients who subsequently become consumptives, how can we be sure that at the time such a diagnosis was made it was by either a dishonest or an incompetent physician? We certainly see ten such patients who recover for one who becomes a consumptive. And great as is my respect for the lung specialists I have yet to meet one who, without examination of the sputa, can at first examination of a patient differentiate tuberculosis from, for instance, the localized bronchopneumonia that so often comes with grippe.

If it is true, as the reader believes, that the general public knows "that in $99 \%$ of cases, hemorrhage means consumption," he surely need not accuse the physicians of Massachusetts of deceiving their patients as to its significance. Hemoptysis may always mean tuberculosis of the lung, but it does not mean inevitable consumption. In fact, such cases are by no means most unfavorable for cure, perhaps because, from fear of further bleeding, such patients are willing to take greater care of themselves.

In many cases it is, of course, true, as Dr. Hawes urges, that the patients should be told at once the nature of their disease and then immediately sent to hospitals. But this is not always the best course to pursue for either the patients themselves or their families. It is not always wise thus to separate the married, or parents from their children. I have seen patients return, with disease thus arrested, to find their former homes devastated. I have known patients who at the sanatoria recovered their health and lost their moral character.

Incipient tuberculosis is generally to be found only 
in the young. Under decent conditions it becomes quiescent. Under exposure or special strain it may become active in after life, especially during early maturity. Can it be seriously urged that in every discovered case of incipient tuberculosis, even in the case of children, the patients themselves are to be immediately told that they are consumptives and then at once to be railroaded to the state hospitals?

Dr. Richard C. Савот: I want first to thank Dr. Hawes a little more than he has yet been thanked. I think he deserves it. The first paper I ever saw of Dr. Hawes' was called "The Early Diagnosis and Aggressive Treatment of Tuberculosis." I think we ought to acknowledge Dr. Hawes as the most aggressive spirit in this anti-tuberculosis fight; many of us have got what enthusiasm we have largely from him.

Dr. Hawes has here applied, as it seems to me, an efficiency test which is a thing all our medical work needs and needs a great deal more than it has ever received. I am glad to hear that the Boston Dispensary has begun to apply an efficiency test to the work of ios clinics. I happened last spring to hear in Wisconsin the paper of Dr. Dearholt, to which Dr. Hawes has referred, and which said, from a slightly different point of view, exactly the same thing that Dr. Hawes has stated. The medical profession of Wisconsin was aghast. Being asked to speak to them I said that I agreed with the paper and I thought that precisely the same thing was true in Massachusetts and in every other state in the Union.

It has been said that we must not trust the patient's statement in the matter. This is true of course. We must not always trust the physician's statement. But I have had some evidence gained by another method and wholly supporting Dr. Hawes' conclusions. I have had an opportunity to teach post-graduate students during the past ten years. I have taught about five hundred graduate physicians from pretty nearly every state in the Union. I think it is no exaggeration to say that $98 \%$ of these gentlemen know nothing about the physical signs of incipient tuberculosis. That is their statement to me, not my statement about them.

I have taken these graduate classes to Rutland where, by the kindness of the trustees and attending physicians, my pupils have had the privilege of examining these cases and it has been the same story year after year. We take a group of incipient cases and the students examine them carefully. When they get through they always say to me (in substance): "What you call advanced we call incipient, and what you call incipient we call normal lungs." I have not myself the least doubt that that is the state of the medical profession throughout the United States, - $98 \%$ of it.

We mustn't forget the fact that this diagnosis is a very difficult one from the physical signs. I think it is true to say that on the whole the history of the patient is going to be of more importance in the recognition of an early case than physical signs, for I don't believe the average general practitioner will be able for many years to recognize incipient tuberculosis from the physical signs. In the first place, the signs are too faint; the number of men who can hear them is comparatively small; then the signs are often disputable. I think if you take any series of incipient cases and give them a careful examination by a group of experts you will find the discrepancy in their findings very remarkable, even as to the question of which lung the disease is in.

I think these facts prove that it is not the fault of patients that we do not get incipient cases. Another thing that seems to me clear is that it is very difficult for the medical schools to teach the diagnosis, by physical signs, of incipient tuberculosis. It is very hard to get the cases to demonstrate, and it is very hard to demonstrate them without killing the patient; it works the patient mighty hard and we cannot work our patients as hard as it is necessary if we are going to teach the students. I think this is true of a considerable number of students at the Harvard Medical and other institutions and I don't see how we are going to overcome it. You can have a hundred students listen to a heart murmur, if the patient is willing, and it doesn't tax the patient. You can't do anything of the kind in incipient tuberculosis. I don't know how to solve that difficulty.

One of the other points that Dr. Hawes has brought up, and which has already been discussed, is the question of lying to patients. I don't believe in lying to anybody about anything and naturally I don't believe in lying about patients. I think Dr. Hawes has made a very strong case. Dr. Worcester has said we mustn't use the word "consumption." It isn't a question of what word we shall use. It is what impression we shall give. If not using the word " consumption" results in the patient not taking proper care, as I know it does in many cases, then we ought to use the word "consumption"; we ought to use whatever word is necessary to make the patient know what he has got and what he ought to do. On the whole, I believe the word "consumption" is the best word. Dangerous in some cases it may be, misleading in some cases, but it is hard to make the patient believe that he must follow the physician's instructions as to how he must live and the conditions of his work, by the use of any other word.

One point has not been presented which seems of importance. I heard this statement made by one of the best physicians, by one of the best diagnosticians, one of the highest-minded men I know in the city of Boston - I do not give his name for certain reasons. He said, "If I knew that I had incipient tuberculosis or any other kind of tuberculosis, I should do absolutely nothing; I should take no treatment and go to no sanatorium." I said, "Why, what on earth do you mean?" He said, "I know you will think I am crazy, but though I might succeed in having the progress of the disease arrested, I should have thereafter to lead an artificial life always. That has been my experience with patients, and I know what happens to those who cannot afford to live an artificial life. I have got to work for my living, and I know perfectly well that going to a sanatorium would make no considerable difference in the long run; therefore, I should do nothing about it if I knew that I had consumption." I think a considerable number of doctors argue from that standpoint, in just the same way; what is the use of telling a man a thing which will not help him. I think when we try to convince the country doctor on this point we are often up against a stone wall. They say, "Did you ever see a case of consumption cured?" I say, "Certainly." They say, "I never saw one." This means that in the class of patients which they see, poor patients, the sanatorium does not in their experience usually work enough good to make it worth while for the patient to be sent there. If they are not going to be sent there, then the prospect is for home treatment, and unless the doctors have a cast-iron, hide-bound rule about veracity, they would not naturally call it tuberculosis or consumption because that does not please the patient.

I feel as Dr. Hawes does that nearly every time we find bacilli we have got to the point where it is no longer incipient and we have got to consider that case as advanced beyond the incipient point. I feel, with Dr. Worcester, that in many cases hemoptysis does not mean tuberculosis. But I think we ought to have the patient understand that he is just as dangerous as if he 
had consumption, and if we do not use the word "consumption" we ought to use some word that makes him just as scared as he ought to be.

Dr. Francis H. Williams: I have been much interested in what has been presented here this evening, having been a student of the subject of pulmonary tuberculosis for a long time, and examiner for the Saranac Sanatorium, for patients coming from this part of the country, for a number of years. I think we should define carefully what we are to understand by incipient tuberculosis. It is a word frequently used, and I think it has a different meaning for different medical men.

As regards diagnosis, it seems to me that we ought in many cases to do better than to make the diagnosis by examination of the sputum. The medical student can do that. The finding of bacilli is a scientific diagnosis, but what might be called the art of medicine enables us often to attain the desired end earlier.

Let me urge what I began advocating a dozen or more years ago, and that is the use of x-ray examinations in pulmonary tuberculosis. When these are generally employed, the number of cases of pulmonary tuberculosis overlooked will be fewer than at present. It would now be possible to find in almost any large clinic in the wards of our great hospitals, where patients are under careful observation, some who would show signs of pulmonary tuberculosis by $\mathrm{x}$-ray examination, but in whom this disease would otherwise fail of recognition. Early cases of pulmonary tuberculosis are certainly not rare, but medical students do not seem to have met them, and unless their attention is especially brought to this subject they may practice a long time without recognizing what I should call an early case of pulmonary tuberculosis.

Let me recall to you my experience with another disease bearing on this question, and cite a patient who was in the City Hospital about fifteen years ago with pneumonia. This case is typical of many others. On the seventeenth day of the disease there were no physical signs in the lungs, so far as I and others could detect, but x-ray examinations made at intervals until the thirty-second day showed increased density there, and on the thirty-second day, although it had diminished, there were still marked and obvious signs of it. Then the patient refused to remain in the hospital, so it is impossible to say for how much longer this increase in density might have been recognized by $x$-ray examinations. If the increase in density in the lungs in pneumonia can be determined by $x$-ray examinations long after it is evident by physical signs, it is natural, as is the case, that increase in density in the lungs in pulmonary tuberculosis can often be recognized before it can be determined by means of the usual physical examination. The reason for this is largely the same in both diseases. Of course, there are other $\mathrm{x}$-ray signs than the increased density of the lungs.

I believe that what I have called precautionary $\mathrm{x}$-ray examinations would be an aid in the early diagnosis of pulmonary tuberculosis. When one member of a family or one member of a group of people working together has this disease, it seems to me advisable that the other members of this family or group should, if possible, seek x-ray examinations at intervals, as it not infrequently happens, when this is done, that some of them are found to have early signs of pulmonary tuberculosis. To discuss $\mathrm{x}$-ray examinations, their difficulties, and how they may mislead if not made by experienced medical men, would be out of place, especially at this late hour.

Dr. Worcester has brought up the question as to whether patients with pulmonary tuberculosis should always be sent to a sanatorium. I quite agree with him that this is not necessary in many cases; for example, when a very early diagnosis is made, improved environment may be sufficient. It should, in my opinion, be our aim to prepare the medical student and assist the general practitioner to make an early diagnosis of pulmonary tuberculosis.

DR. M. J. KonIKow: Dr. Konikow in his remarks called attention to the social aspects of the tuberculosis problem and urged that these be given more serious consideration by the medical profession.

DR. E. O. OTIS: The problem of the early diagnosis of pulmonary tuberculosis is an ever-present and insistent one. For failure to make an early diagnosis the general practitioner has had to endure a very considerable amount of blame, both justly and unjustly in my opinion.

In order that no one in the incipient stage should escape, every person would have to be examined, which is obviously impossible. Neither can the physician go about hunting up possible cases who do not think or realize that anything is the matter with them, or enough to warrant their consulting the doctor. $\mathrm{He}$ is not to be blamed for this. Again, the physician has not the time, nor will the patient always pay for or even submit to an examination of the lungs when he consults his physician for some other malady; although if the physician did examine, as a routine measure, the lungs of every patient who consulted him, for whatever cause, he would undoubtedly discover some, or perhaps many, cases of incipient tuberculosis.

It is a very different thing when the patient comes to the expert who has the time and is paid enough for a careful examination. With many patients, often long distances to cover and small fees, it is not always possible for the general practitioner to make a painstaking examination, involving much time and energy, of every suspected case, as much as he would like to do so. Granting, however, that he can and is willing to devote the time for such an examination, whether properly remunerated or not for it, difficulties arise inherent in making the diagnosis itself.

In the first place, it is not infrequently of extreme difficulty to make a diagnosis of a suspected case at the first examination. Every expert knows this. Then, again, both teachers and textbooks perplex the physician by not only giving a mass of signs and symptoms to be looked for, - some of the first and some of minor importance, - but also by differently emphasizing them, some asserting that one set of signs is the most important, while others put the emphasis upon a different combination, due, perhaps, to personal experience and training.

Again, I am not sure that we have not been overemphasizing the importance of the physical signs to the neglect of the symptoms. Perhaps Paterson, of the Frimly Sanatorium, is nearer right when he goes so far as to say that he is guided by the symptoms even to the disregard of the physical signs. A careful investigation of the symptoms and the recognition of their different values will, I believe, in the majority of cases, put one on the right track; and this every practitioner can do, even if he feels himself unable to detect and interpret slight changes in the physical examination. Many a diagnosis can be made upon Norris's quartet of early ascertained symptoms: (a) Rapid pulse; (b) evening rise of temperature; (c) loss of weight; (d) cough, - the protracted existence of any two of which, he says, require that good cause should be shown why a diagnosis of tuberculosis should not be made.

Slight changes in the percussion note and the re- 
spiratory sound are often difficult of detection and interpretation, especially for one who has not a finely attuned ear or who has not had much experience, and the most skilled diagnostician is sometimes baffled. It is said of the elder Flint that he used to play upon his violin every day in order that his ear might be readily responsive to slight changes of pitch or note in chest examinations. We cannot, therefore, expect the general practitioner to make a definite diagnosis upon such changes alone; it is asking him to do what the expert is often unable to do. If, however, he will carefully observe and study the symptoms, and will only take account of such physical signs as he is sure of, particularly localized râles, and will examine the sputum, he will usually be successful in making a diagnosis, I believe.

So far as physical signs are concerned, the great mass of practitioners have regarded, and will continue, I believe, to regard the localized râle as the most important, although when detected it may not always mean an early diagnosis. Râles are unmistakable, they are absolutely abnormal, while other signs " represent merely deviations from the normal."

Again, the difference between clinical - active tuberculosis and anatomical - inactive - tuberculosis is not always clearly discerned and this may mislead the physician. An individual may show the physical signs of tuberculosis but he may have no symptoms and suffer no deterioration of health; he is, therefore, practically well and requires no treaiment. Another may have no determinable physical signs but definite symptoms of the disease; he, on the other hand, is suffering from active tuberculosis and requires treatment.

When the diagnosis of early clinical tuberculosis is made, the general practitioner again is often unjustly blamed for not instituting prompt treatment. The patient may not appreciate the gravity of his condition and will not submit to rigorous treatment, or he feels that he must take the risks and continue his work for the support of those dependent upon his labors. We have all met with examples of this. Or, if he realizes the danger, he has also learned from the experience of others the stigma left upon one if it becomes known that he has had tuberculosis and the difficulty of obtaining employment afterwards. As desirous as the conscientious physician may be to institute prompt treatment, either in a sanatorium or under his own supervision at home, his efforts are often rendered futile by the patient or his friends from these or other causes, and so the case drags on untreated, and from no fault of the physician.

What is the remedy? The universal dissemination of knowledge regarding tuberculosis in general, and regarding the results obtained when the disease is treated early, at the right time, when arrest is probable; or late, at the wrong time, when death is probable; the establishment of free dispensaries; examination of workshop and factory operatives; better medical inspection of schools; some form of automatic provision of families of tuberculous individuals while they are under treatment, perhaps a workman's compensation law against sickness, as now exists in this state against accidents; more assurance of employment when cured; special instruction and training in medical schools in early diagnosis; and, finally, the deeper and fundamental remedy, - prevention of all those causes which lower normal resistance: poverty from a non-living wage; bad housing; insanitary and dusty workshops; alcohol; and all the other preventable causes.

DR. Vincent Y. Bowditch: It is not a pleasant thing to seem to stand as a critic of one's professional brethren, and it is very easy for us to see the beam in the brother's eye before plucking out that in our own. There are times, however, when it may be necessary for those who are working in special lines to strongly emphasize certain facts to which they feel that others are not giving proper attention, and this may be done in no spirit of carping criticism but with a sincere desire to help.

With the attitude which Dr. Hawes takes in his paper, in regard to the failure of many practitioners to detect the early signs of tubercular disease, he has my sincere sympathy. Fortunately, I think, there has been a marked change for the better in the last few years in this respect; and yet I cannot enumerate the cases which have come to my attention in which definite symptoms of beginning disease have been manifested in patients who have been allowed to go on for months in ignorance of their true condition, for fear, on the physicians' part, of unnecessarily alarming them, or for other reasons best known to the medical advisers themselves. We must all recognize the fact that in the rush and hurry of general practice it may often be impossible for a conscientious physician to give a patient the thorough examination he is entitled to when suspicious symptoms are present, but I regard it as little short of criminal if such a patient be allowed to go on indefinitely without an atlempt being made to establish a definite diagnosis. We can blame no one who simply, from lack of experience, fails to detect slight signs of incipient disease, if he has at least examined his patient conscientiously; but blame should be placed upon any one who fails under such conditions to give the patient ihe benefit of expert advice when it is possible to get it. Neglect to do this means loss of time that is vital to the patient, and disaster that might have been averted follows. Over and over again I have had patients tell me that they had complained of certain suspicious symptoms months before to their own physician, only to be put off without thorough examination, with the statement that they merely had a "bronchial " or "stomach cough," and no attempt made to examine the spuca.

Incidentally I may mention an instance of one of the rather discouraging aspects of the knowledge of tubercular disease in the profession. A practitioner brought a patient to me after months of ineffective treatment at home, with the statement that tubercle bacilli had been found two or three times a few months before, but asked me if I felt that that was positive proof of the presence of tuberculosis, although there was additional proof of disease upon examination of the chest! It is hard to see why a practitioner who would not hesitate to call in expert advice in a case of suspected appendicitis should fail to do so in a doubtful case of pulmonary disease, the early diagnosis of which is equally important as far as the patient's life is concerned.

Dr. Hawes has spoken of the plan which has been adopted in recent years, since the establishment of the Massachusetts Tuberculosis Commission, of throwing open the admission of patients to Rutland and the other sanatoria to the whole profession, instead of leaving it to special examiners, as it was at first. For the reasons before given, it was inevitable that a much larger number of far-advanced, practically hopeless cases were admitted to Rutland, thereby injuring it as a sanatorium in the strict sense. I say this in no spirit of unkind criticism of the yeoman service that this commission has done for the state. They have had to meet the most difficult problems and have met them well; but it is a matter upon which they may be congratulated that they have recently declared that stricter rules would be made about the admission and 
retention of the less hopeful cases at Rutland, in order that we may have at least one large institution which is kept to its original purpose, - a place where people can be restored to health in a large percentage of cases.

There is a great deal of useless and harmful talk at present about our having "begun at the wrong end" in our endeavor to eradicate tuberculosis, or at least to control it. People are apt to say that because sanatorium treatment has not accomplished everything, it is, therefore, of no use, - an utterly foolish and untrue statement. Those who have had most to do with this question have for years been urging the necessity of attacking the disease from every side, and have urged the necessity of hospitals for advanced cases near our large towns as one of the most important steps; but we need hospitals, sanatoria, home treatment, tuberculosis schools, every means, in short, for combating the disease, and as far as it is possible I regard it as essential that far-advanced cases should not be admitted with the hopeful cases in sanatoria.

If, however, we wish to accomplish the end we are working for in the shortest way, it is necessary for the profession at large to awaken to the importance of not shillyshallying with suspicious cases; of seeing that patients are thoroughly examined, and that if there be doubt at all as to the nature of any given case, expert advice should be asked for without delay. In my opinion, if a physician fails on these points, he is recreant to his trust as one who is supposed to look out for the welfare of the community.

DR. HAWES: It has been a hard and not very pleasant task to collect these figures which I have shown, which do not throw an altogether favorable light upon us physicians. I believe, however, that there has been shown to exist a serious condition of affairs in this lack of the prompt and early diagnosis of consumption. How to remedy these existing conditions is a problem which I believe we should all face fairly and squarely. If the figures that I have shown to-night will make the problem clearer and easier of solution I shall be very glad.

I feel that the best part of what has been said this evening is not my paper, but the discussion which it has brought out, and to those who have taken part in this discussion I am very grateful.

\section{THE INFLUENCE OF RACE IN THE PREVA- LENCE OF TUBERCULOSIS.}

BY FRANCIS P. MC CARThY, M.D.,

Pathologist, St. Elizabeth's Hospital; Late Resident Physician, Boston Consumptives' Hospital, Mattapan.

From association with tuberculosis in home, dispensary and hospital practice for the past six years I have been tremendously impressed by the marked variation in the course of tuberculosis met with in the various races of people in the United States and the tropics.

From the apparent almost hopelessness of this disease among the Indian and negro races to a far more favorable outlook in the Hebrew, we readily see how racial influences stand out prominently to workers in this disease as factors in the study and control of tuberculosis.

The-influence of racial variations in immunity and susceptibility plays an all-important rôle in the prognosis of the disease, and also in methods of attack and control of this terrible scourge.

* Read at meeting of Norfolk District, Massachusetts Medical Society, Dec. 26, 1911 .
Practically all my observations in regard to tuberculosis among the negro and Indian, together with certain mixed races of the tropics, were noted during a two years' service in the Canal Zone, Panama. A close association with the disease among the different white races in and about Boston has been made possible by living with these patients in hospitals for a period of four years, the last two being spent in the Boston Consumptives' Hospital at Mattapan, which has at present a capacity of 250 cases of tuberculosis.

Various writers have covered the ground thoroughly as regards the prevalence of the disease in different races, especially Woods Hutchinson, ${ }^{1}$ whom I quote freely in some of the remarks of this paper; but I feel there are a few unmentioned facts in the prevalence of tuberculosis in certain races which would be interesting to note.

A table showing the relative mortality from tuberculosis in the different races is here shown.

Indian (nine reservations),

Negroes (United States Census, 1900),

Negroes (Rural United States),

Chinese (Cities),

Irish (New York City, 1890)

Irish (Total United States, 1900),

Japanese,

Scandinavians,

Italians, Per 100,000

2,800

750

400

700

650

400

300

280

220

American Whites,

210

Polish Jews,

170

Let us first consider the race having the lowest mortality, namely, the Jewish people. Anybody who has come in contact with this disease to any extent cannot help being impressed with the decided relative immunity manifested by the Hebraic race against this disease. Living as the Jewish people do in the congested cities, the majority of them under very crowded conditions, it is interesting to note the relative low mortality from this disease among them. Their unusual resistance is shown more clearly when we consider the large number of emaciated, overworked employees of the sweat-shops, and the relatively lower mortality among these people than among the more sturdy Irish population.

There can be but little doubt that Jews are peculiarly resistant to microbic disease in general. During the Middle Ages, when epidemics of various diseases carried off a large percentage of the population, their immunity was so marked and their low death-rate by comparison with the rest of the population so noticeable, that they were often accused of poisoning the wells. ${ }^{2}$ It is said that they have an especial fitness for residence in malarial districts.

Various reasons may be given for the unusual resistance of the Jewish people to tuberculosis. While tuberculous meats as a source of contagion only play a very minor rôle in the spread of tuberculosis, it is reasonable to believe that the rigid inspection of their meat which is practiced to a high degree among a large percentage of the Jews undoubtedly does limit their danger of infection from this source.

The Jews, essentially a sober and temperate 